\title{
Swedish national survey on MR safety compared with CT: a false sense of security?
}

\author{
Boel Hansson ${ }^{1,2}$ (D) Johan Olsrud ${ }^{1,2} \cdot$ Jonna Wilén $^{3} \cdot$ Titti Owman $^{1,2} \cdot$ Peter Höglund ${ }^{4}$. \\ Isabella M. Björkman-Burtscher ${ }^{1,2,5}$
}

Received: 25 April 2019 / Revised: 20 August 2019 / Accepted: 18 September 2019 / Published online: 13 December 2019

(C) The Author(s) 2019

\begin{abstract}
Objectives The objectives were to survey MR safety incidents in Sweden during a 12-month period, to assess severity scores, and to evaluate the confidence of MR personnel in incident-reporting mechanisms.

Method Data were collected within a web-based questionnaire on safety in clinical MR environments with CT for comparison. Data reported MR and CT safety incidents (human injury, material damage, and close calls), incident severity, and confidence of participants in incident-reporting systems.

Results The study population consisted of 529 eligible participants. Participants reported $200 \mathrm{MR}$ and $156 \mathrm{CT}$ safety incidents. Among MR incidents, $16 \%$ were given the highest potential severity score. More MR workers (73\%) than CT workers (50\%) were confident in being aware of any incident occurring at their workplace. However, $69 \%$ MR workers (83\% for CT) were not aware of reported incidents at their hospitals.

Conclusion Safety incidents resulting in human injury, material damage, and close calls in clinical MR environments do occur. According to national risk assessment recommendations, risk level is high. Results indicated that MR personnel tend to a false sense of security, as a high proportion of staff members were sure that they would have been aware of any incident occurring in their own department, while in reality, incidents did occur without their knowledge. We conclude that false sense of security exists for MR.

Key Points

- Safety incidents in clinical MR environments still result in human injury and material damage.

- Severity level of MR incidents - assessed using Swedish national risk assessment recommendations-is high.

- Confidence of MR personnel in incident-reporting mechanisms is high, but reflects a false sense of security, as a high proportion of staff is unaware of reported incidents in the same workplace.
\end{abstract}

Keywords Safety management · Magnetic resonance imaging $\cdot$ Risk assessment $\cdot$ Surveys and questionnaires $\cdot$ Patient safety

Boel Hansson

boel.hansson@med.lu.se

1 Department of Medical Imaging and Physiology, Skåne University Hospital, Lund, Sweden

2 Department of Diagnostic Radiology, Clinical Sciences, Lund University, Lund, Sweden

3 Department of Radiation Sciences, Umeå University, Umeå, Sweden

4 Department of Clinical Pharmacology, Clinical Sciences, Lund University, Lund, Sweden

5 Department of Radiology, Clinical Sciences, Sahlgrenska Academy, University of Gothenburg, Gothenburg, Sweden

\section{Introduction}

For MR safety, three types of electromagnetic field exposure must be considered: the static magnetic field, the gradient magnetic field, and the radio-frequency field [1]. In some individuals, when moving through it, the static magnetic field causes shortterm effects such as vertigo and nausea, but no serious adverse effects have been reported [2-4]. The hazard of projectiles, attracted by the static magnetic field, is the most dangerous risk in MR $[5,6]$. Translational forces on ferromagnetic objects in and outside the body are more pronounced with today's actively shielded magnets since the spatial gradient-the rate of change of the static magnetic field with respect to distance-is steep [7]. 
The time-varying gradient magnetic field present during image acquisition may lead to peripheral nerve stimulation, cause acoustic noise, and/or affect implants. When MR safety standards are adhered to, peripheral nerve stimulation can be kept below the level of concern [8], and injury due to acoustic noise $[6,9]$ or harmful induction of electrical currents in implants, such as pacemakers, can be prevented [10-13].

The radio-frequency coil transfers energy into the body and can cause heating. Currents are induced in electrically conductive tissue or implants, and heating may occur due to resistance to the current [7]. MR safety procedures are aimed at prevention of potential thermal risks in electrically conductive materials, at ensuring that tissues do not form electrically conductive loops, and at raising awareness of other factors (e.g., tattoos) that constitute a possible heating risk [14].

Safety-related incidents may increase as the number of scanners installed increases [15]. Although already in 1994 Boutin et al [16] had pointed out the importance of screening procedures, it was not until an MR-unsafe oxygen tank had killed a 6-year-old boy [17] that the first guidelines for MR safety were developed [14]. This tragic event was even preceded by two other projectile-related close calls, neither adequately communicated among local staff nor leading to re-evaluation of safety procedures [18].

Incident-reporting systems are essential to be aware of incidents, understand their causes, and prompt action for prevention avoiding future human suffering and also saving hospital costs [19-22].

MR in clinical practice is still not completely safe. Thus, the aims of this national web-based survey in Sweden were to survey MR safety incidents that occurred over a 12-month period, to assess incident severity and to evaluate confidence of MR personnel in incident-reporting mechanisms. Further, we compared with CT personnel as a control group.

\section{Material and methods}

\section{Survey}

This study was part of a national web-based questionnaire focusing on the working environment for MR workers and on safety issues for patients and personnel with $\mathrm{CT}$ for comparison.

MR vendors provided a list of installed bases in Sweden and personal contact was made with each site to identify a person responsible for $\mathrm{MR}$ and/or CT who could distribute information about the study and post a link to the questionnaire. Data were collected over a 6-month period, and personnel scanning to any degree with MR and/or CT were eligible to participate; thus, the survey targeted primarily MR and CT radiographers.

\section{Background population}

Sweden, a country with approximately 10 million inhabitants, had at the time of the survey $92 \mathrm{MR}$ sites for human imaging (information collected from vendors and verified by personal contact) with more than 225 scanners (information collected from survey). The number of MR users, defined as personnel regularly scanning humans and thus mainly referring to MR radiographers, was for Sweden estimated to be approximately 620 (information collected from contact persons at all MR sites). The equivalent estimate of CT users, at the MR sites that also had CT, was approximately 1300.

\section{Study population and workplaces}

The following demographic data were collected: numbers of MR and/or CT workers who responded; age; gender; full-time or part-time work; percentage of full time (full time $=40 \mathrm{~h} /$ week) dedicated to work with MR, CT, and other modalities (e.g., ultrasound, conventional radiology) or administration; modality experience; number and type(s) of hospitals represented and their installed base; and patient demographics (e.g., clinical, research, level of care, care burden).

\section{Safety data}

Data on safety incidents focused on human injuries, material damage, and close calls. The participants stated whether they were aware of any safety-related incidents that had occurred at their hospital during the last 12-month period before participation in the survey, including a voluntary free-text description of the incidents, to classify incidents and exclude double reports. Free-text comments were not mandatory to allow protection of the integrity of the participants and to decrease the risk of under-reporting due to fear of recognition, an issue emphasized during ethical evaluation of the study design. Participants were also asked if they were confident that any safety incidents that might have occurred at their workplace would have come to their attention (confidence in incidentreporting mechanisms). Questions on safety were repeated for MR and CT for comparison, allowing participants working with both modalities to fill in a complete set of safety questions for both modalities. There is no national register for safety incidents, and hospitals are only encouraged to report any preventable serious incidents that have or might have led to human injury to the health and social care inspectorate, a government agency. 


\section{Data evaluation and statistics}

Demographic data on the study population and on safety incidents are reported with descriptive statistics. Safety incidents resulting in human injury were first processed with an assessment of a severity score based on free-text comments and adapted national recommendations for risk assessment and incidence analysis [23]. The score is based on the National Patient Safety Improvement Handbook [24], and only considers human injury. Mainly, immediate consequences were expected to be mentioned in the free-text comments, as personnel at radiology departments usually has not the opportunity to follow up on long-term outcome after incidents, which might differ for very severe incidents, where feedback loops are expected to be more efficient, not the least due to possible legal consequences. Further, all safety incidents were scored with a potential severity score defining the potential worstcase scenario outcome of a similar incident. Scores were as follows: $1=$ minor (discomfort or insignificant injury); 2 = intermediate (transient sensory, motor, physiological, intellectual, or mental disability; extended care episode; or increased care level); 3 = significant (persistent moderate sensory, motor, physiological, intellectual, or mental impairment; extended care episode; or increased care level); and $4=$ catastrophic outcome (death, persistent major sensory, motor, physiological, intellectual or mental disability). Scoring was performed during a consensus discussion regarding each safety incident by the head MR safety physicist (JO), the head MR safety research radiographer (TO), the responsible research radiographer $(\mathrm{BH})$, and the Principal Investigator of the study, a neuroradiologist with 20 years of experience (IBB).

McNemar's chi-square test with continuity correction was used to evaluate potential differences in confidence in incident-reporting mechanisms regarding MR and CT in individuals working with both modalities. Mann-Whitney $U$ test and Wilcoxon signed-rank test were used for evaluation of group differences.

\section{Results}

\section{Study population and workplaces}

In total, 529 eligible answers were registered after exclusion of 17 questionnaires submitted incompletely or by participants who were not eligible. Figure 1 gives numbers and reasons for exclusion of submitted questionnaires. Of the 529 participants, $415(78 \%)$ were women (mean age 46 years, median 48 , range 23-66), 112 (21\%) were men (mean age 43 years, median 43, range 25-65), and two participants did not define their gender. Only 7 participants were not radiographers (5 biomedical analysts, 1 physicist, and 1 nurse).

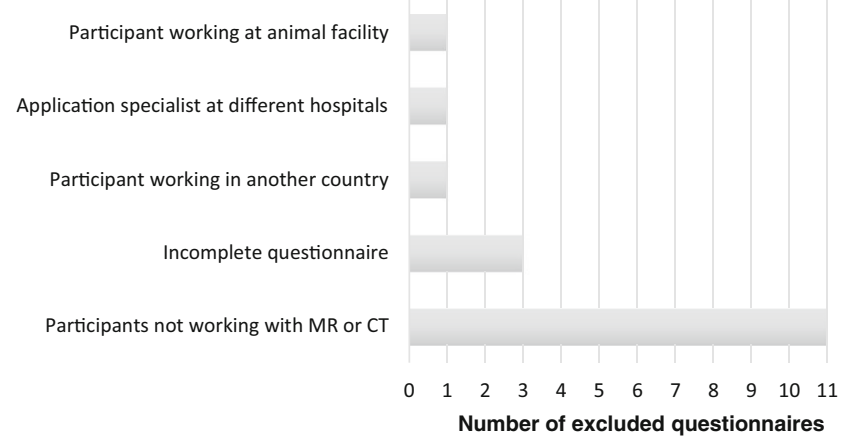

Fig. 1 Reasons for exclusion of 17 questionnaires (total submitted 546)

Of the participants, 345 worked part time or full time with MR, 392 worked part time or full time with CT, 137 with MR but not CT, 184 with CT but not MR, and 208 with both MR and CT. Part-time work with other modalities is not reported here due to its limited relevance. When the work time was compared, MR had a significantly higher level of work hours than CT (Wilcoxon signed-rank test, $p=0.007$ ). Table 1 is a summary of data on self-estimated percentage of total work time that was designated by the 529 participants to the two modalities under investigation, MR and CT, and Fig. 2 shows the individual distribution for the participants.

The normal working hours in Sweden for radiographers are $40 \mathrm{~h}$ per week, but individual working hours may vary due, for example, to part-time contracts, or part-time sick leave or parental leave. Fifteen participants reported that they worked $<75 \%$ of normal working hours, 80 participants worked $75-90 \%$ of normal working hours, and 434 participants worked $91-100 \%$ of normal working hours (40 h/week).

Mean experience for participants working with MR was 8 years (median 14; range $0-32$ years) and mean CT experience was 12 years (median 10; range $0-38$ years).

Prior to the survey, we established by personal contact the number of hospitals with MR units to be 92 in Sweden. The 529 participants in the survey worked at 86 hospitals ( 9 private); 167 (32\%) of them worked at 12 hospitals affiliated to the seven medical universities in the country. The estimated response rate of MR workers was approximately $60 \%$. The survey covered most MR scanners in the country, as all large hospitals were covered and the majority non-covered by the survey $(n=11)$ were small private MR facilities $(n=7)$. The participants working with MR in the study therefore worked at 81 hospitals, entailing approximately 225 MR scanners; and the participants working with CT worked at 84 hospitals with $253 \mathrm{CT}$ installations.

The numbers of MR and CT scanners at each hospital or healthcare unit varied between 1 and 7 for MR (median 2) and 1-6 for CT (median 3). The most common MR scanner was a 1.5-T scanner (334 users), followed by 3-T installations (133 users). The most common CT scanner was 64-slice scanner (288 users), followed by 128 -slice scanner (122 users). 
Table 1 Self-estimated percentage of total work time designated by participants to MR or CT

Participants $(n)$ working with modality

\begin{tabular}{l}
\hline $0-100 \%<50 \%$ \\
Of the full-time equivalent of $40 \mathrm{~h} /$ week
\end{tabular}

\begin{tabular}{|c|c|c|c|c|c|}
\hline MR & 345 & 165 & 113 & 67 & $56 ; 4-100$ \\
\hline CT & 392 & 295 & 86 & 11 & $39 ; 4-100$ \\
\hline MR but not CT & 137 & 9 & 61 & 67 & $83 ; 10-100$ \\
\hline CT but not MR & 184 & 102 & 71 & 11 & $51 ; 9-100$ \\
\hline
\end{tabular}

Figure 3 shows the percentage of participants working with clinical examinations, research, interventions, method development, and other unspecified tasks regarding the modalities in question. MR and CT showed similar distributions except for intervention, which was much more common in CT than in MR. For MR, the estimated percentage of patients with higher care burden was slightly lower than that for CT (Fig. 4).

\section{Safety incidents}

Altogether, 200 MR safety incidents and 156 CT safety incidents were reported by the 529 participants. The numbers of human injuries, material damage, and close calls related to MR and CT are detailed in Table 2, together with information on multiple reporting of specified incidents, the number of participants reporting the incidents, the number of hospitals affected, and the number of participants working with the modality in question at these hospitals. Exclusion of multiple reporting was performed based on evaluation of the free-text comment, and reduced the number of specified incidents by a mean of $33 \%$ for MR and $19 \%$ for CT (Table 2).

Details of specified reported safety incidents are given in Table 3, together with severity scores of the incidents. The

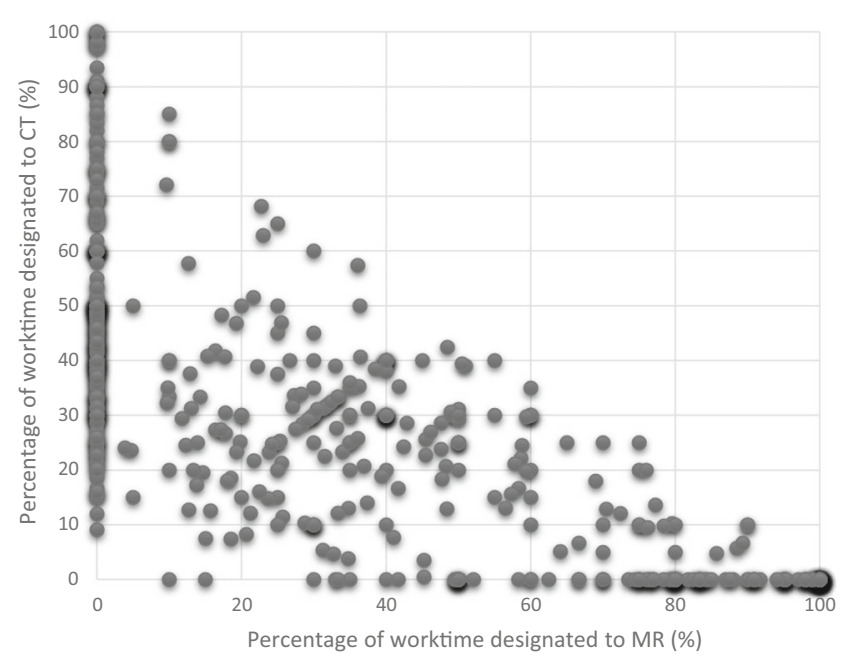

Fig. 2 Self-estimated percentage of total work time designated to MR and/or CT for the 529 participants pattern of incidents that were further specified by participants and evaluated after exclusion of multiple reporting differed between MR $(n=97)$ and CT $(n=51)$. MR users focused mainly on incidents related to the static magnetic field, the radio-frequency field, and the gradient magnetic field (projectiles, implants, and burns) $(n=92)$, whereas CT users focused on radiation issues $(n=3)$ and complications related to application of contrast media $(n=12)$, a topic that was not at all touched upon by any of the MR users. Incidents related to ergonomics $(n=41)$, with a mixture of heavy lifts of equipment or patients, and clamping and squeezing incidents involving equipment, affecting patients and personnel were reported for both modalities but more often by CT users $(n=36)$ than by MR users $(n=5)$. Material damage and close calls were more often reported by MR users than by CT users (Table 2); however, human injuries were more common for CT. Although not specifically requested, participants who used the voluntary free-text option commented about whom they regarded to be responsible for MR safety incidents: personnel from departments other than radiology (44 incidents), personnel from radiology (13 incidents), or a patient or relative (16 incidents); but for 24 incidents, the responsible party was unspecified.

Assessment of severity of human injuries based on freetext descriptions gave severity scores of 1 to 3 for MR and 1 to 4 for CT, where the case with score 4 in $\mathrm{CT}$ refers to an anaphylactic reaction to contrast media with fatal outcome (Table 3). In all MR cases, potential-worst-case scenario-severity scores were higher than actual severity scores for human injuries, but unchanged for CT (Table 3). A summary of projectiles involved in safety incidents is given in Fig. 5.

\section{Confidence in incident-reporting mechanisms}

Data on confidence in incident-reporting mechanisms are given in Table 4 for MR and CT workers. More MR workers than CT workers were confident that any safety incidents or close calls that might have occurred at their workplace would have come to their notice (mean for human injuries, material damage, and close calls: $73 \%$ of MR workers vs. $50 \%$ of CT 
Fig. 3 Percent of participants working with clinical examinations, research, interventions, method development, and/or other unspecified tasks regarding MR and CT

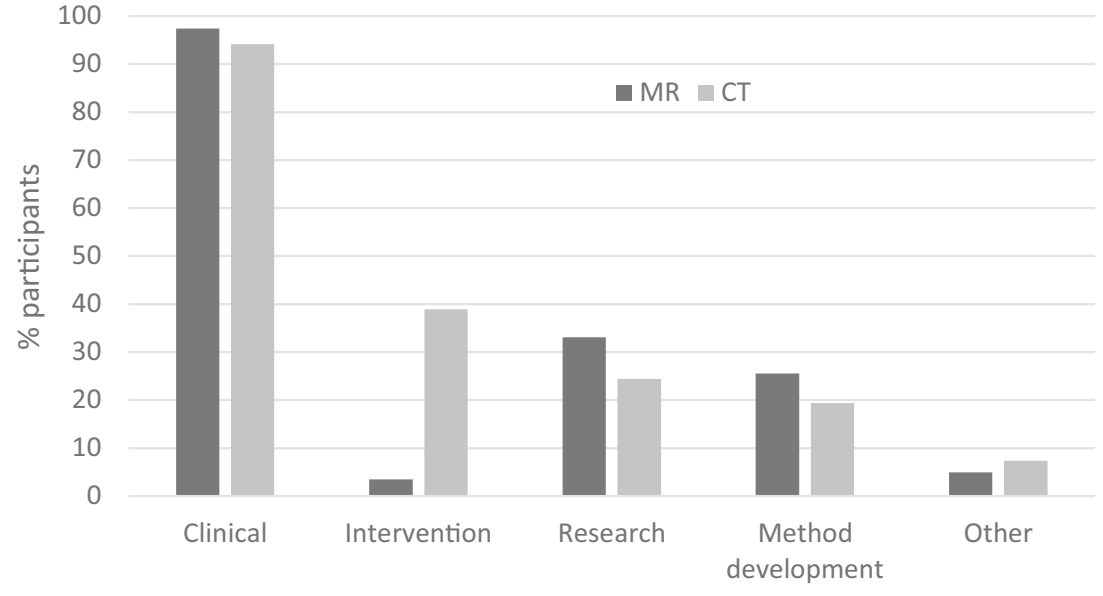

workers). The proportion of MR workers who reported that they were not aware of any incidents at their workplace(s)—although other participants at their workplace had reported a safety incident-was somewhat lower (mean for human injuries, material damage, and close calls; 69\%) than for CT workers (83\%), but was very high in both groups despite the fact that both MR workers and CT workers had a high confidence in incident-reporting mechanisms.

When we only considered participants working with both modalities $(n=208)$, the participants were significantly more confident that any safety incident that might have occurred at their workplace concerning MR would have come to their attention than regarding any safety incidents concerning CT (McNemar's chi-square test with continuity correction; $p<0.0005$ for human injury, material damage, and close call) (Table 5).

\section{Discussion}

As there is no national register for MR-related safety incidents in Sweden, this national survey was performed to gain a baseline overview of MR safety incidents that occurred in the country over a 12 -month period. With a response rate of approximately $60 \%$ of all MR workers in Sweden, covering $90 \%$ of hospitals/facilities with MR units in Sweden, the 21 human injuries, 50 cases of material damage, and 129 close calls reported should cover the majority of MR safety incidents that occurred during the study period. At hospitals with incidents reported, $82 \%$ of MR users did not report having knowledge of any incident. An average of $61 \%$ of these users do not acknowledge the possibility that incidents might have occurred without their knowledge (65\% for human injury, $62 \%$ for material damage, and $57 \%$ for close calls). This finding suggests that the healthcare system lacks functioning local incident-report systems assuring feedback to employees. This is also reflected by the rather low percentage of multiple reporting of specific incidents. Further, radiographers working with both MR and CT had significantly higher confidence in safety feedback regarding MR than $\mathrm{CT}$ incidents $(p<0.0005)$, illustrating that the efficacy of feedback mechanisms at a department may differ for modalities or be perceived differently. Reported MR incidents were mainly related to burns and projectiles, and were thereby related to the static magnetic field, or the radio-frequency
Fig. 4 Percent of participants working with the different care burden categories in MR and CT

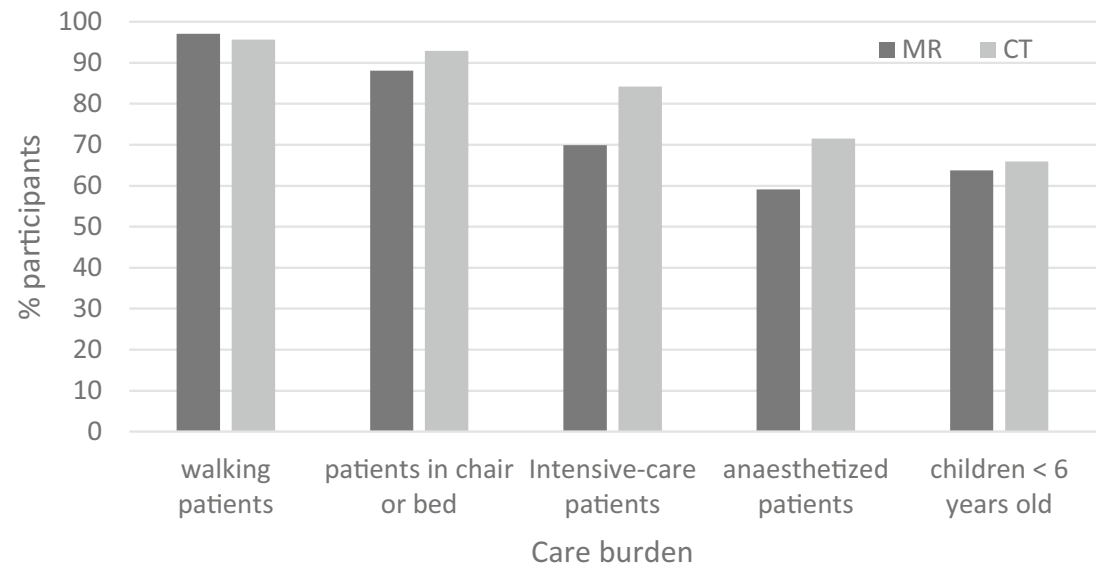


Table 2 Safety incidents reported by 345 MR workers at 81 hospitals and 392 CT workers at 84 hospitals

\begin{tabular}{|c|c|c|c|c|c|c|c|c|}
\hline \multicolumn{2}{|c|}{$\begin{array}{l}\text { Safety incident and } \\
\text { modality evaluated }\end{array}$} & \multirow{3}{*}{$\begin{array}{l}\text { Reported incidents } \\
\left(n_{\text {tot }} ; n_{\text {spec }} ; n_{\text {spec_ex }}\right)\end{array}$} & \multirow{3}{*}{$\begin{array}{l}\text { Hospitals }(n) \text { with } \\
\text { reported incidents }\end{array}$} & \multirow{3}{*}{$\begin{array}{l}\text { Participants not } \\
\text { reporting incidents, } n(\%)\end{array}$} & \multicolumn{4}{|c|}{ Participants $n(\%)$ working at hospitals } \\
\hline & & & & & \multicolumn{3}{|c|}{ With reported incidents } & \multirow{2}{*}{$\begin{array}{l}\text { Without reportec } \\
\text { incidents }\end{array}$} \\
\hline & & & & & Total & $\begin{array}{l}\text { Reporting } \\
\text { an incident }\end{array}$ & $\begin{array}{l}\text { Not reporting } \\
\text { incidents }\end{array}$ & \\
\hline \multirow[t]{2}{*}{ HI } & MR & $21 ; 18 ; 11$ & 11 & 326 (94) & 87 & $19(22)$ & $68(78)$ & 258 \\
\hline & $\mathrm{CT}$ & $64 ; 30 ; 25$ & 23 & $359(92)$ & 177 & $33(19)$ & $144(81)$ & 215 \\
\hline \multirow[t]{2}{*}{ MD } & MR & $50 ; 34 ; 21$ & 15 & 308 (89) & 116 & $37(32)$ & 79 (68) & 229 \\
\hline & CT & $39 ; 18 ; 14$ & 15 & 369 (94) & 152 & $23(15)$ & $129(85)$ & 240 \\
\hline \multirow[t]{2}{*}{$\mathrm{CC}$} & MR & $129 ; 93 ; 65$ & 33 & $263(76)$ & 201 & $82(41)$ & 119 (59) & 144 \\
\hline & $\mathrm{CT}$ & $53 ; 15 ; 12$ & 17 & 369 (94) & 145 & $23(16)$ & $122(84)$ & 247 \\
\hline \multirow[t]{2}{*}{ Total } & MR & $200 ; 145 ; 97$ & 37 & 306 (89) & 220 & $39(18)$ & $181(82)$ & 125 \\
\hline & $\mathrm{CT}$ & $156 ; 63 ; 51$ & 34 & 329 (84) & 248 & $63(25)$ & $185(75)$ & 144 \\
\hline
\end{tabular}

$H I$, human injury; $M D$, material damage; $C C s$, close calls; $n_{\text {tot }}$, total number of reported incidents; $n_{\text {spec }}$, number of incidents further specified with freetext comment in questionnaire; $n_{\text {spec_ex }}$, number of specified incidents excluding multiple reporting (further detailed in Table 3 ), as identified by hospital affected and description of incident

Table 3 Numbers of safety incidents $(n)$, which were further specified by participants in voluntary free-text comments, grouped according to cause and evaluated regarding severity score (SS) for actual human injuries and potential severity score (PSS) based on worst-case scenarios for all safety incidents. Scores range from 1 (minor) to 4 (catastrophic)

\begin{tabular}{|c|c|c|c|c|c|c|c|c|c|c|c|c|c|c|}
\hline & \multicolumn{7}{|c|}{ MR } & \multicolumn{7}{|l|}{ CT } \\
\hline & \multicolumn{3}{|c|}{ Human injury } & \multicolumn{2}{|c|}{ Material damage } & \multicolumn{2}{|c|}{ Close call } & \multicolumn{3}{|c|}{ Human injury } & \multicolumn{2}{|c|}{ Material damage } & \multicolumn{2}{|c|}{ Close call } \\
\hline & $n$ & $\mathrm{SS}$ & PSS & $n$ & PSS & $n$ & PSS & $n$ & SS & PSS & $n$ & PSS & $n$ & PSS \\
\hline Burns (total) & $5^{\mathrm{a}}$ & 2 & 3 & 0 & - & 0 & - & 0 & - & - & 0 & - & 0 & - \\
\hline Projectile (total) & 3 & $1-2$ & 3 & 19 & $2-4$ & 57 & $2-4$ & 0 & - & - & 0 & - & 0 & - \\
\hline Small, blunt & 0 & & & $3^{\mathrm{b}}$ & 2 & $15^{\mathrm{c}}$ & 2 & & & & & & & \\
\hline Small sharp/median size & $3^{\mathrm{d}}$ & $1-2$ & 3 & $15^{\mathrm{e}}$ & 3 & $31^{\mathrm{f}}$ & 3 & & & & & & & \\
\hline Large/heavy metal & 0 & & & $1^{\mathrm{g}}$ & 4 & $11^{\mathrm{h}}$ & 4 & & & & & & & \\
\hline Implant (total) & 0 & - & - & 0 & - & 8 & $2-4$ & 0 & - & - & 0 & - & 0 & - \\
\hline Pacemaker & & & & & & 3 & 4 & & & & & & & \\
\hline Splinter close to eye & & & & & & 1 & 3 & & & & & & & \\
\hline Other & & & & & & $4^{i}$ & 2 & & & & & & & \\
\hline Ergonomics (total) & $3^{j}$ & 1 & 2 & $2^{k}$ & 2 & 0 & - & $14^{1}$ & $1-2$ & $1-2$ & $14^{\mathrm{m}}$ & 2 & $8^{\mathrm{n}}$ & 2 \\
\hline Contrast medium (total) & 0 & - & - & 0 & - & 0 & - & 9 & $1-4$ & $1-4$ & 0 & - & 3 & $1-4$ \\
\hline Air injection & & & & & & & & & & & & & 2 & 4 \\
\hline Extravasation & & & & & & & & 6 & 1 & 1 & & & 1 & 1 \\
\hline Needle-stick & & & & & & & & 2 & 1 & 1 & & & & \\
\hline Adverse reaction & & & & & & & & $1^{\circ}$ & 4 & 4 & & & & \\
\hline Radiation dose & & & & & & & & $2^{\mathrm{p}}$ & 1 & 1 & 0 & - & 1 & 1 \\
\hline Total $n /$ max. score & 11 & 2 & 3 & 21 & 4 & 65 & 4 & 25 & 4 & 4 & 14 & 2 & 12 & 4 \\
\hline
\end{tabular}

Severity scores: 1 = minor (discomfort or insignificant injury), 2 = intermediate (transient sensory, motor, physiological, intellectual, or mental disability; extended care episode; or increased care level), 3 = significant (persistent moderate sensory, motor, physiological, intellectual, or mental impairment; extended care episode; or increased care level), 4 = catastrophic outcome (death or persistent major sensory, motor, physiological, intellectual, or mental disability). Italics indicate total

Short explanations of objects/actions involved, with number of incidents given in parenthesis (n): $a$, skin-skin contact or loop (1), skin-coil contact (3), unspecified (1); $b$, glasses (1), hair clip (1), equipment part (1); $c$, hair pin (1), screw (1), keys (3), basket lid (1), phone (3), unspecified metal object in pocket (6); $d$, unspecified sharp object (1), unspecified magnetic object (1); wheelchair (1); $e$, scissors or knife (2), crutches (1), wheelchair (3), walker (2), ventilator/monitor (3), infusion pump (2), vacuum cleaner (1), cart (1); $f$, scissors or knife (7), crutches (2), laryngoscope (2), forceps (2), wheelchair (4), rescue stretcher (1), walker (6), ventilator/monitor (1), infusion pump (4), cleaning cart (1), cart (1); $g$, oxygen tank (1); $h$, oxygen tank (5), bed (6); $i$, leg prosthesis (1), tracheal tube (1), undefined metal implant (2); $j$, heavy lift/bumping into equipment (3); $k$, squeeze from equipment during table movement (2); $l$, strain injury due to heavy lift or bumping into equipment affecting personnel (10), squeeze of body part of personnel or patient from equipment (4); $m$, collision between patient bed and CT table, CT table lowered onto equipment—often patient bed, clothes, or equipment stuck during table movement (14); $n$, clothes or equipment close to getting stuck/squeezed during table movement in any direction (2), body parts close to getting squeezed during table movement or patient transfer (2), close to bumping into equipment (2), risk of strain injury due to heavy lift (1), risk of patient falling when leaving the table before it was lowered as intended (1); $o$, anaphylactic reaction to contrast medium with fatal outcome (1); $p$, radiation dose increased due to re-scan (2) 


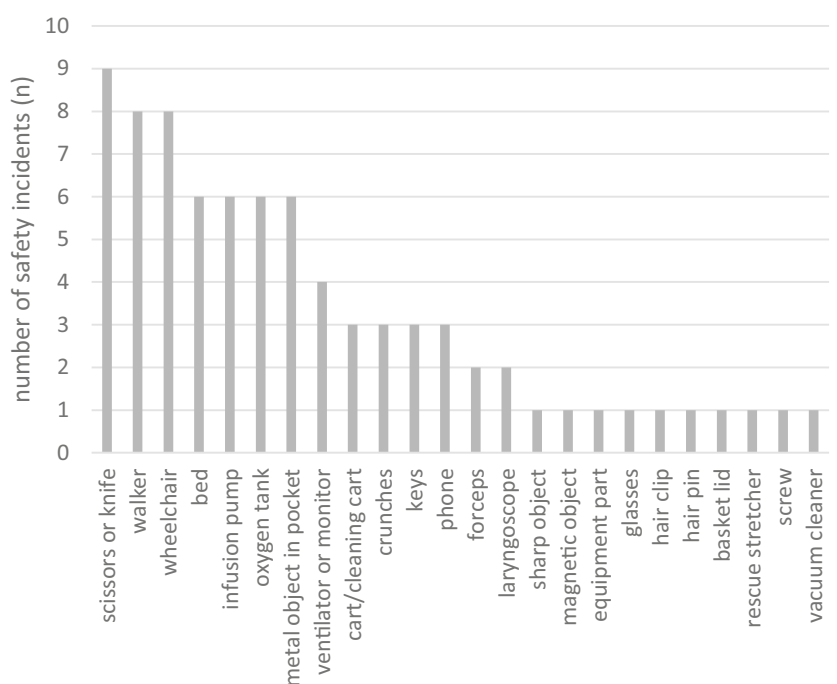

Fig. 5 Short descriptions of projectiles involved in safety incidents $(n)$ specified by participants in voluntary free-text comments

field. Safety incidents related to ergonomic risks affected both patients and personnel and were mainly raised by CT users, which might be related to the larger throughput of patients at CT compared to MR. Reported close calls were predominant among MR safety incidents in this study, and we interpret this finding as reflecting a considerable awareness of safety risks and that safety practices and routines are in place as a necessary base for MR accident prevention. No lethal cases were reported for MR in this study. However, as a high number of close calls has been reported

Table 4 Numbers of participants $(n ; \%)$ working with MR and/or CT who were confident (C) (bold) or were not confident (NC) (italics) that safety incidents that might have occurred at their own hospital, and involving their modality, would have come to their notice. Participants have

Participants working at hospitals Participants who did (yes) or did with (yes) or without (no) reported not (no) report any safety incidents safety incidents involving large items such as wheelchairs, ventilators, oxygen tanks, and beds, several lethal cases could have happened, inciting again on the necessity to adopt international recommendations for safety $[13,25-28]$. This is also reflected in the fact that $15(16 \%)$ MR safety incidents specified were given the highest potential-worst-case scenario-severity score. James reported that serious harm seems to be $10-20$-fold more common than lethal harm [29].

MR-related risks are manifold, and incident prevention is complex and relies heavily on employees and thus patients become vulnerable in MR environments. Factors to minimize this vulnerability are continuously reviewed safety routines, staff education, feedback mechanisms on incidents, and the much more numerous close calls, and a change of culture towards learning from mistakes [11, 14, 16, 30-32]. Further, confidence in internal communication or local reporting systems might be much greater than the true usefulness of such routines, as shown in this study, and they need to be designed carefully [19]. Even if most MR sites in Sweden have safety screening checklists, advocated as single most effective measure for prevention [33], MR safety incidents still occur. Radiographers, radiologists, personnel from other departments accompanying patients to MR units, administrative staff, janitors, and firemen are important pieces of the MR safety puzzle, and leaving out one piece might jeopardize security and possibly lead to a catastrophe [28].

Based on our results showing that severe adverse events still exist, are poorly shared within the team, and are

been grouped according to whether or not they worked at hospitals with reported safety incidents and whether or not they reported incidents themselves

\begin{tabular}{|c|c|c|c|c|c|c|}
\hline & & & & & \\
\hline & & & & Human injury & Material damage & Close call \\
\hline \multirow[t]{6}{*}{ MR } & \multirow[t]{2}{*}{ Yes } & \multirow[t]{2}{*}{ Yes } & Confident & 15 & 32 & 63 \\
\hline & & & Not confident & 4 & 5 & 19 \\
\hline & \multirow[t]{2}{*}{ Yes } & \multirow[t]{2}{*}{ No } & Confident & 44 & 49 & 68 \\
\hline & & & Not confident & 24 & 30 & 51 \\
\hline & \multirow[t]{2}{*}{ No } & \multirow[t]{2}{*}{ No } & Confident & 208 & 181 & 101 \\
\hline & & & Not confident & 50 & 48 & 43 \\
\hline \multirow[t]{6}{*}{$\mathrm{CT}$} & \multirow[t]{2}{*}{ Yes } & \multirow[t]{2}{*}{ Yes } & Confident & 22 & 13 & $-{ }^{\mathrm{a}}$ \\
\hline & & & Not confident & 11 & 10 & $-{ }^{\mathrm{a}}$ \\
\hline & \multirow[t]{2}{*}{ Yes } & \multirow[t]{2}{*}{ No } & Confident & 62 & 47 & 49 \\
\hline & & & Not confident & 82 & 82 & 73 \\
\hline & \multirow[t]{2}{*}{ No } & \multirow[t]{2}{*}{ No } & Confident & 121 & 102 & 112 \\
\hline & & & Not confident & 95 & 138 & 136 \\
\hline
\end{tabular}

\footnotetext{
${ }^{a}$ Due to a design problem in the questionnaire 14, participants, who reported a close call for CT, could not answer the question on confidence in incidentreporting mechanisms, and are thus not included in this evaluation
} 
Table 5 Breakdown of participants working both with MR and CT ( $n=$ 208) who were confident (yes) or not confident (no) that any safety incidents that might have occurred at their workplace, concerning MR and $\mathrm{CT}$, would have come to their attention

\begin{tabular}{clllllll}
\hline & \multicolumn{2}{l}{ Human injury } & \multicolumn{2}{l}{ Material damage } & \multicolumn{2}{c}{ Close call $^{\mathrm{a}}$} \\
\hline \multicolumn{2}{l}{ Confident } & MR & & & & & \\
& & No & Yes & No & Yes & No & Yes \\
CT & No & 50 & 39 & 49 & 43 & 70 & 38 \\
& Yes & 8 & 111 & 11 & 105 & 12 & 74 \\
\hline
\end{tabular}

${ }^{\text {a }}$ Due to a design problem in the questionnaire 14 participants, who reported a close call, could not answer the question on confidence in incident-reporting mechanisms, and thus not included in this evaluation

preventable, the following action steps are mandatory: (1) identify potential risk zones; (2) design specific educational programs dedicated to every category of professionals that work in or might visit MR sites with a focus on vigilance of MR personnel on potential mistakes made by other professionals, potential misunderstandings, or knowledge gaps; (3) state clear MR safety procedures including screening forms that are confirmed with an interview just before entering the MR-scanner room; and (4) facilitate rigorous but easily manageable incident-reporting systems with focus on prevention and learning from mistakes.

This nationwide survey well represents the MR environment in the country and is also internationally generalizable regarding many aspects. However, a survey of this kind can never claim to have complete coverage, and always leaves room for selection bias. Both underestimation and duplicate recording may have occurred. Incidents involving large and more hazardous objects might be more frequently reported than incidents with smaller and less hazardous objects. Also Mansouri et al [34] have pointed out that incident-reporting systems inherently suffer from under-reporting.

From an ethical point of view and to protect the integrity of employees, answers were completely anonymous and data are presented avoiding identification of specific facilities and their association with particular incidents. This limited the possibility of double-checking incidents, although similar descriptions of incidents in the free-text comments, concerning incidents occurring at the same hospital, have been detected and lead to exclusion of multiple reporting. However, to encourage participants not to hold back due to fear of individual identification, the free-text comment for specification of incidents was optional.

Our assessment of severity scores based on adapted national recommendations [23] can of course not be compared to a full-scale risk assessment based on detailed data concerning a specific incident. However, putting the reported and specified incidents into a severity context is of great importance, to highlight possible future risks and in MR safety-prevention work.
We chose to use CT for comparison in this study, in order to be able to put the results in a similar context, and due to the many similarities between the two work environments. Limitations of this approach are, for example, the significantly higher proportion of full-time working hours dedicated to the modality of MR, compared to CT, observed in this study and the known difference in throughput of examinations per hour for the two modalities.

In conclusion, this national survey has shown that safety incidents resulting in human injury, material damage, and close calls in clinical MR environments do occur. Risk level of these incidents is high. Results indicated that MR personnel tend to have a false sense of security, as a high proportion of staff members were sure that they would have been aware of any incident occurring in their own department, while in reality, incidents did occur without their knowledge. Using CT for comparison highlighted that individuals might consider safety and feedback differently, depending on the modality.

Acknowledgements We want to direct our special thoughts towards coauthor Prof. Peter Höglund, who passed away during the publication process of this paper. His contribution was invaluable and we will miss him during our research endeavours to come.

Funding information Open access funding provided by Lund University. This study has received funding by the Skåne University Hospital foundations and donations and the Academy of Care Science, Skåne University Hospital, Lund, Sweden.

\section{Compliance with ethical standards}

Guarantor The scientific guarantor of this publication is Isabella M Björkman-Burtscher.

Conflict of interest The authors of this manuscript declare no relationships with any companies, whose products or services may be related to the subject matter of the article.

Statistics and biometry One of the authors has significant statistical expertise.

Informed consent Written informed consent was not required for this study because informed consent was given by submitting the web-based questionnaire. Withdrawal from the study after submission was not possible, as the data were collected anonymously.

Ethical approval Approval was obtained from the appropriate regional ethical board.

\section{Methodology}

- Observational

- Web-based national survey

- Performed at one institution

Open Access This article is distributed under the terms of the Creative Commons Attribution 4.0 International License (http:// creativecommons.org/licenses/by/4.0/), which permits unrestricted use, distribution, and reproduction in any medium, provided you give 
appropriate credit to the original author(s) and the source, provide a link to the Creative Commons license, and indicate if changes were made.

\section{References}

1. Hartwig V, Giovannetti G, Vanello N, Lombardi M, Landini L, Simi S (2009) Biological effects and safety in magnetic resonance imaging: a review. Int J Environ Res Public Health 6(6):1778-1798

2. Chakeres DW, de Vocht F (2005) Static magnetic field effects on human subjects related to magnetic resonance imaging systems. Prog Biophys Mol Biol 87(2-3):255-265

3. Shellock FG, Crues JV (2004) MR procedures: biologic effects, safety, and patient care. Radiology 232(3):635-652

4. Glover PM (2015) Magnetic field-induced Vertigo in the MRI environment. Curr Radiol Rep 3(29):1-7

5. Schenck JF (2000) Safety of strong, static magnetic fields. J Magn Reson Imaging 12(1):2-19

6. Coskun $\mathrm{O}$ (2011) Magnetic resonance imaging and safety aspects. Toxicol Ind Health 27(4):307-313

7. Panych LP, Madore B (2018) The physics of MRI safety. J Magn Reson Imaging 47(1):28-43

8. Schaefer DJ, Bourland JD, Nyenhuis JA (2000) Review of patient safety in time-varying gradient fields. J Magn Reson Imaging 12(1):20-29

9. Shellock FG, Ziarati M, Atkinson D, Chen DY (1998) Determination of gradient magnetic field-induced acoustic noise associated with the use of echo planar and three-dimensional, fast spin echo techniques. J Magn Reson Imaging 8(5):1154-1157

10. Shulman RM, Hunt B (2018) Cardiac implanted electronic devices and MRI safety in 2018 - the state of play. Eur Radiol 28:4064 4065

11. Ferris NJ, Kavnoudias H, Thiel C, Stuckey S (2007) The 2005 Australian MRI safety survey. AJR Am J Roentgenol 188(5): 1388-1394

12. Shellock FG, Crues JV (2014) MRI bioeffects, safety, and patient management. Biomedical research publishing group, Los Angeles

13. Keevil S (2016) Safety in magentic resonance imaging. MPI J 4(1): 26-34

14. Kanal E, Barkovich AJ, Bell C et al (2013) ACR guidance document on MR safe practices: 2013. J Magn Reson Imaging 37(3): $501-530$

15. De Wilde J, Grainger D, Price DL, Renaud, C (2007) Magnetic resonance imaging safety issues including an analysis of record incidents within UK. Prog Nucl Magn Reson Spectrosc 51:37-48

16. Boutin RD, Briggs JE, Williamson MR (1994) Injuries associated with MR imaging: survey of safety records and methods used to screen patients for metallic foreign bodies before imaging. AJR Am J Roentgenol 162(1):189-194

17. Chen D (2001) Boy, 6, dies of skull injury during M.R.I. The New York Times, New York. Available via https://www.nytimes.com/ 2001/07/31/nyregion/boy-6-dies-of-skull-injury-during-mri.html. Accessed 24 July 2019

18. Gilk TAM, Latino R (2011) MRI safety 10 years later. Patient Safety \& Quality Healthcare, Middleton. Available via https:// www.psqh.com/analysis/mri-safety-10-years-later/. Accessed 24 July 2019
19. Jones DN, Benveniste KA, Schultz TJ, Mandel CJ, Runciman WB (2010) Establishing national medical imaging incident reporting systems: issues and challenges. J Am Coll Radiol 7(8):582-592

20. Soop M, Fryksmark U, Koster M, Haglund B (2009) The incidence of adverse events in Swedish hospitals: a retrospective medical record review study. Int J Qual Health Care 21(4):285-291

21. Baker GR, Norton PG, Flintoft V et al (2004) The Canadian Adverse Events Study: the incidence of adverse events among hospital patients in Canada. CMAJ 170(11):1678-1686

22. Vincent C, Neale G, Woloshynowych M (2001) Adverse events in British hospitals: preliminary retrospective record review. BMJ 322(7285):517-519

23. Sveriges Kommuner och Landsting (2015) Handbok för riskanalys och händelseanalys - Analysmetoder för att öka patientsäkerheten 2015. Sveriges Kommuner och Landsting, Stockholm. Available via https://webbutik.skl.se/sv/artiklar/riskanalys-ochhandelseanalys-analysmetoder-for-att-oka-patientsakerheten.html. Accessed 1 April 2019

24. U.S. Department of Veterans Affairs (2011) NCPS Patient Safety Improvement Handbook. U.S. Department of Veterans Affairs, Washington DC. Available via https://www.patientsafety.va.gov/ professionals/publications/handbook.asp. Accessed 24 July 2019

25. Shellock FG, Spinazzi A (2008) MRI safety update 2008: part 2, screening patients for MRI. AJR Am J Roentgenol 191(4):1140 1149

26. Medicines and healthcare products regulatory agency (2015) Safety guidelines for magnetic resonance imaging equipment in clinical use. Medicines and healthcare products regulatory agency, London. Available via https://assets.publishing.service.gov.uk/ government/uploads/system/uploads/attachment data/file/476931/ MRI_guidance_2015_-_4-02d1.pdf. Accessed 24 July 2019

27. Calamante F, Ittermann B, Kanal E, Inter-Society Working Group on MR safety, Norris D (2016) recommended responsibilities for management of MR safety. J Magn Reson Imaging 44(5):10671069

28. Clausen L, Cook J, Garlock A et al (2018) Radiologic technologist best practice for MR safety. American society of radiologic technologists, Albuquerque. Available via https://www.asrt.org/docs/ default-source/publications/whitepapers/asrt 18 mrsafetywhitepaper.pdf?sfvrsn=6. Accessed 24 July 2019

29. James JT (2013) A new, evidence-based estimate of patient harms associated with hospital care. J Patient Saf 9:122-128

30. Edmondson AC (2004) Learning from failure in health care: frequent opportunities, pervasive barriers. Qual Saf Health Care 13(Suppl II):ii3-ii9

31. Schultz SR, Watson RE Jr, Prescott SL et al (2011) Patient safety event reporting in a large radiology department. AJR Am J Roentgenol 197:684-688

32. Price MR, Williams TC (2018) When doing wrong feels so right: normalization of deviance. J Patient Saf 14:1-2

33. Dempsey MF, Condon B, Hadley DM (2002) MRI safety review. Semin Ultrasound CT MR 23(5):392-401

34. Mansouri M, Aran S, Harvey HB, Shaqdan KW, Abujudeh HH (2015) Rates of safety incident reporting in MRI in large academic medical center. J Magn Reson Imaging 43:998-1007

Publisher's note Springer Nature remains neutral with regard to jurisdictional claims in published maps and institutional affiliations. 